Article

Subscriber access provided by King Abdullah University of Science and Technology Library

\title{
Tailored strength neighboring group interactions switch polymerization to dimerization catalysis
}

Eva Schiebel, Stefano Santacroce, Laura Falivene, Inigo Göttker-Schnetmann, Lucia Caporaso, and Stefan Mecking

ACS Catal., Just Accepted Manuscript • DOI: 10.1021/acscatal.9b00129 • Publication Date (Web): 21 Mar 2019

Downloaded from http://pubs.acs.org on March 28, 2019

\section{Just Accepted}

"Just Accepted" manuscripts have been peer-reviewed and accepted for publication. They are posted online prior to technical editing, formatting for publication and author proofing. The American Chemical Society provides "Just Accepted" as a service to the research community to expedite the dissemination of scientific material as soon as possible after acceptance. "Just Accepted" manuscripts appear in full in PDF format accompanied by an HTML abstract. "Just Accepted" manuscripts have been fully peer reviewed, but should not be considered the official version of record. They are citable by the Digital Object Identifier (DOI®). "Just Accepted" is an optional service offered to authors. Therefore, the "Just Accepted" Web site may not include all articles that will be published in the journal. After a manuscript is technically edited and formatted, it will be removed from the "Just Accepted" Web site and published as an ASAP article. Note that technical editing may introduce minor changes to the manuscript text and/or graphics which could affect content, and all legal disclaimers and ethical guidelines that apply to the journal pertain. ACS cannot be held responsible for errors or consequences arising from the use of information contained in these "Just Accepted" manuscripts. 


\section{INTRODUCTION}

In catalytic insertion polymerizations a control of chain growth vs. chain transfer is paramount to achieve desired polymer molecular weights and material properties. The relevant pathways can involve cocatalysts and chain transfer reagents, but especially depend on the active transition metal site itself. This is most pronounced for late transition metal catalysts, which are generally prone to B-H elimination (BHE), a key step of chain transfer. ${ }^{1}$

Late transition metal polymerization catalysts are outstanding in their synthetic scope in that they can tolerate heteroatomcontaining polar substrates and solvents. Further, they can provide a unique branching microstructure. These arise from 'chain walking' by repeated sequences of BHE and olefin reinsertion. ${ }^{2}$ To use the potential of such catalysts, a control of the underlying pathways is required. Notably, both a suppression of BHE as well as its promotion are of practical interest. A complete suppression enables the formation of ultra high molecular weight strictly linear polyethylene (PE), which is formed in a desirable non-entangled state. ${ }^{3-4}$ On the other hand, hyperbranched oligomer materials have potential as lubricants or surface modifiers..$^{5-6}$

An instructive case with regard to these general issues are $\mathrm{N}$-terphenyl salicylaldiminato $\mathrm{Ni}(\mathrm{II})$ catalysts (Scheme 1)..$^{7-8}$ Salicylaldiminato $\mathrm{Ni}$ (II) catalysts in general stand out in being highly active for ethylene polymerization and at the same time stable toward water and compatible with certain vinyl monomers. ${ }^{7}$, 9-12
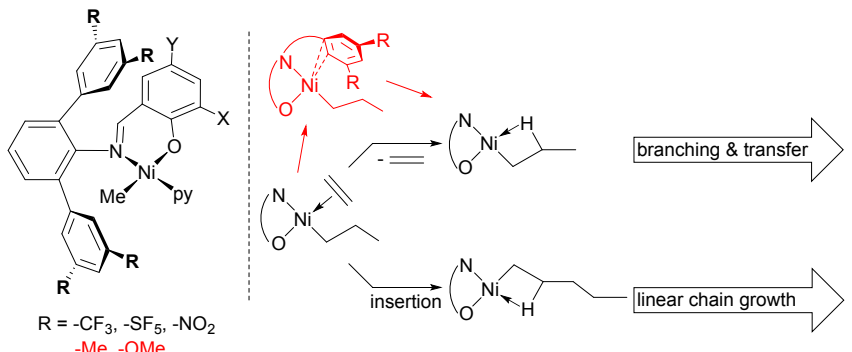

Scheme 1. N-Terphenyl salicylaldiminato Ni(II) catalysts and mechanism of weak neighboring group interactions' promoting chain transfer and branch formation.

Despite their rather remote position, substituents on the distal rings of the aforementioned terphenyl motif effect the products of catalysis dramatically. ${ }^{13-14}$ With electron-withdrawing substituents, high molecular weight linear PE is formed while with electrondonating substituents under otherwise identical conditions hyperbranched low molecular weight polymers are obtained. This has been traced to a weak interaction of the distal aryl rings with the $\mathrm{Ni}(\mathrm{II})$ center, which promotes decoordination of ethylene and hereby favors BHE and consequently chain transfer and branch formation. ${ }^{15}$ Only with electron-rich substituted aryls this weak 
interaction is operative. Notably, also for other late transition metal catalyst structures the role of substituents' attractive 'secondary' interactions with substrates and the active site is being revealed. ${ }^{16-}$ 18

This recently gained understanding provokes the question how stronger such neighbouring group interactions affect catalysis, that is promote certain pathways strongly without shutting down activity due to blocking of the active site. We now show that appropriately placed additional O-donors hit this spot.

\section{RESULTS AND DISCUSSION}

As a potentially coordinating additional donor, we introduced -OAryl groups in the 2,6 potition of the well known salicylaldimnato motif (Figure 1). The phenoxy substitution itself is expected to have a minor impact on the electronic properties on the $\mathrm{N}$-donor as given by the Hammet constant. ${ }^{19}$
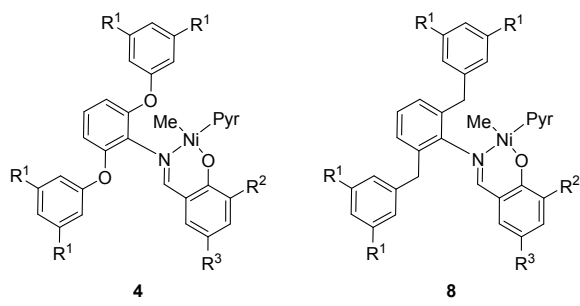

Figure 1: Structures of the complexes $\mathbf{4}$ and $\mathbf{8}$ prepared in this work.

As a reference, another set of catalysts bearing non-coordinating methylene groups instead of the oxygen atoms were targeted. A structurally related, but sterically more crowded ligand structure was reported by Chen and coworkers. ${ }^{20}$ These catalysts with a dibenzhydryl moiety were highly active within the first ten minutes of polymerization and produce high molecular weight $\mathrm{PE}$ with a moderate degree of branching. ${ }^{20}$

\section{Synthesis and characterization of the complexes.}

Synthesis. 2,6-difluoronitrobenzene was substituted in a nucleophilic aromatic substitution with modified phenols (Scheme 2). ${ }^{21}$
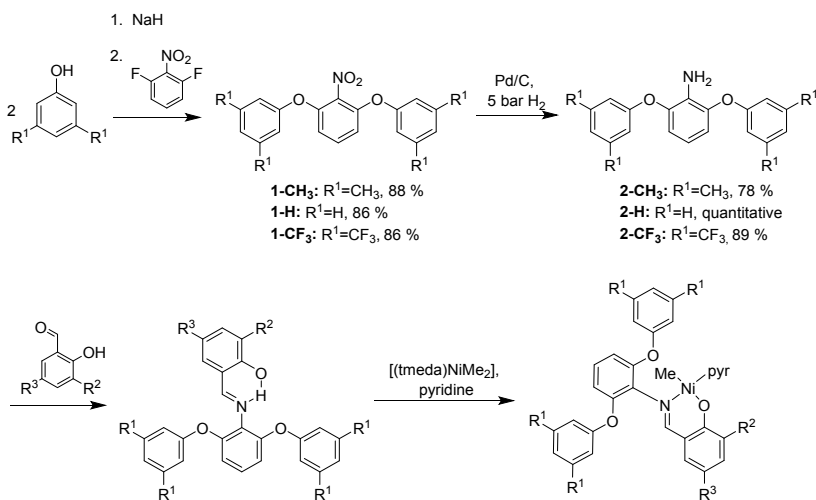

$-\mathrm{CH}_{3}-12: \mathrm{R}^{1}=\mathrm{CH}_{3}, \mathrm{R}^{2}, \mathrm{R}^{3}=\mathrm{I}$, quantitative 3-H-12: $\mathrm{R}^{1}=\mathrm{H}, \mathrm{R}^{2}, \mathrm{R}^{3}=\mathrm{I}, 81 \%$ $3-\mathrm{CF}_{3}-12: \mathrm{R}^{1}=\mathrm{CF}_{3}, \mathrm{R}^{2}, \mathrm{R}^{3}=1,58 \%$ 4-H-12: $R^{1}=H, R^{2}, R^{3}=I, 92 \%$ 4- $\mathrm{CH}_{3}$-ant: $\mathrm{R}^{1}=\mathrm{CH}_{3}, \mathrm{R}^{2}=9$-anthryl, $\mathrm{R}^{3}=\mathrm{H}, 94$ 3-H-ant: $R^{1}=H, R^{2}=9$-anthryl, $R^{3}=H, 66 \%$
3-CF

Scheme 2. Synthesis of oxygen bridged complexes.
To allow a fine tuning of the anticipated weak interactions, three phenols with electron withdrawing or donating substituents were used. The obtained nitro benzenes were reduced according to a reported procedure ${ }^{21}$ and used without further purification in the following condensation step. The anilines were reacted with either 3,5-diiodosalicylaldehyde or 2-hydroxy-3-(9anthryl)benzaldehyde in an acid-catalyzed reaction in methanol. The obtained salicylaldimines are poorly soluble in methanol, enabling the generation of analytically clean products by washing with solvent. All six different salicylaldimines were reacted with [(tmeda) $\left.\mathrm{NiMe}_{2}\right]$ in the presence of pyridine to give the oxygen bridged complexes $\mathbf{4}$ in good yields.

The anilines for the methylene bridged complexes were synthesized based on a procedure by Knochel et. al. ${ }^{22}$ (Scheme 3). To this end, organozinc compounds with different substitution patterns were prepared and used directly (after filtration) in a C-C coupling reaction with 2,6-dibromoaniline. The substituted anilines were condensed with 3,5-diiodosalicylaldehyde or 2-hydroxy-3-(9anthryl)benzaldehyde in toluene. The salicylaldimines were obtained after purification by column chromatography. The complexes were obtained by reacting the salicylaldimines with [(tmeda) $\left.\mathrm{NiMe}_{2}\right]$ and pyridine in benzene (for full characterization data $\mathrm{cf}$. the Supporting Information, SI).
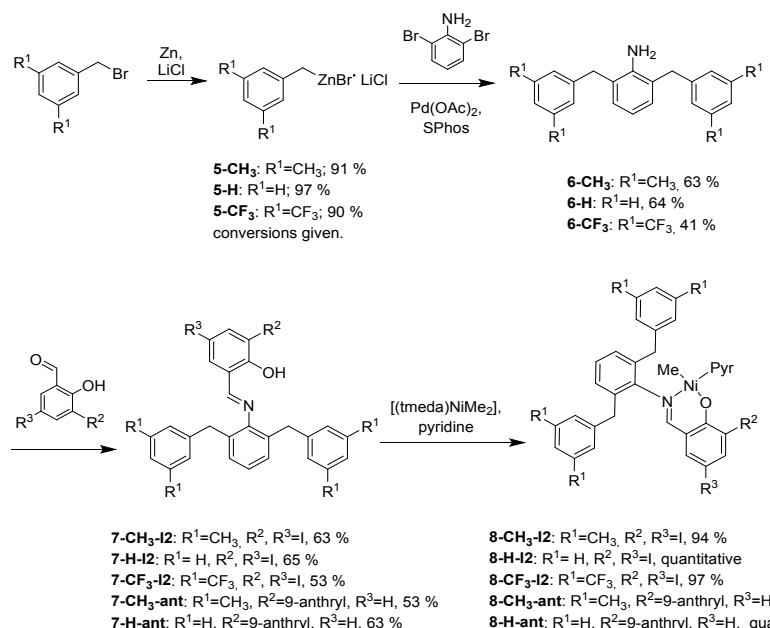

8- $\mathrm{CH}_{3}-12: \mathrm{R}^{1}=\mathrm{CH}_{3}, \mathrm{R}^{2}, \mathrm{R}^{3}=1,94 \%$ 8-H-12: $\mathrm{R}^{1}=\mathrm{H}, \mathrm{R}^{2}, \mathrm{R}^{3}=\mathrm{I}$, quantitative $8-\mathrm{CF}_{3}-12: \mathrm{R}^{1}=\mathrm{CF}_{3}, \mathrm{R}^{2}, \mathrm{R}^{3}=1,97 \%$ 7-CH $\mathrm{CH}_{3}$-ant: $\mathrm{R}^{1}=\mathrm{CH}_{3}, \mathrm{R}^{2}=9$-anthryl, $\mathrm{R}=\mathrm{H}$ 7-CF -ant: $^{1}=\mathrm{CF}_{3}, \mathrm{R}^{2}=9$-anthryl, $\mathrm{R}^{3}=\mathrm{H}, 57 \%$

8- $\mathrm{CH}_{3}$-ant: $\mathrm{R}^{1}=\mathrm{CH}_{3}, \mathrm{R}^{2}=9$-anthryl, $\mathrm{R}^{3}=\mathrm{H}, 92 \%$ 8-H-ant: $R^{1}=H, R^{2}=9$-anthryl, $R^{3}=H$, quantitative - $\mathrm{CF}_{3}$-ant: $\mathrm{R}^{1}=\mathrm{CF}_{3}, \mathrm{R}^{2}=9$-anthryl, $\mathrm{R}^{3}=\mathrm{H}, 92 \%$

Scheme 3. Synthesis of methylene bridged complexes.

Properties. The electron density on the Ni-atom is directly correlated to the catalytic properties. ${ }^{15}$ To this end, forward peak potentials obtained by cyclic voltammetry (CV) measurements of the $\mathrm{Ni}(\mathrm{II}) / \mathrm{Ni}(\mathrm{III})$ pair are a probe for the electronic properties of the complexes (Table 1).

Table 1: Forward peak potentials from cyclic voltammetry measurements.

$\begin{array}{lcccc}\# & \text { complex } & \text { bridge } & \mathbf{R}^{\mathbf{1}} & \mathbf{E}[\mathbf{m V}]^{\mathbf{a}} \\ \mathbf{1} & 4-\mathrm{CH}_{3}-\mathrm{I} 2 & \mathrm{O} & \mathrm{CH}_{3} & -98 \\ \mathbf{2} & 4-\mathrm{H}-\mathrm{I} 2 & \mathrm{O} & \mathrm{H} & -65 \\ \mathbf{3} & 4-\mathrm{CF}_{3}-\mathrm{I} 2 & \mathrm{O} & \mathrm{CF}_{3} & 192 \\ \mathbf{4} & 4-\mathrm{CH}_{3} \text {-ant } & \mathrm{O} & \mathrm{CH}_{3} & 7^{\mathrm{b}} \\ \mathbf{5} & 4-\mathrm{H}_{-} \text {-ant } & \mathrm{O} & \mathrm{H} & \text { n.d.c } \\ \mathbf{6} & 4-\mathrm{CF}_{3} \text {-ant } & \mathrm{O} & \mathrm{CF}_{3} & 283 \\ \mathbf{7} & \text { 8- } \mathrm{CH}_{3}-\mathrm{I} 2 & \mathrm{CH} & \mathrm{CH}_{3} & 189\end{array}$




$\begin{array}{ccccc}\mathbf{8} & \text { 8-H-I2 } & \mathrm{CH}_{2} & \mathrm{H} & 228 \\ \mathbf{9} & \text { 8-CF }-\mathrm{C} 2 & \mathrm{CH}_{2} & \mathrm{CF}_{3} & 356 \\ \mathbf{1 0} & \text { 8- } \mathrm{CH}_{3} \text {-ant } & \mathrm{CH}_{2} & \mathrm{CH}_{3} & 113 \\ \mathbf{1 1} & \text { 8-H-ant } & \mathrm{CH}_{2} & \mathrm{H} & 139 \\ \mathbf{1 2} & \text { 8- } \mathrm{CF}_{3} \text {-ant } & \mathrm{CH}_{2} & \mathrm{CF}_{3} & 308\end{array}$

${ }^{a}$ Determined from cyclic voltammetry against $\left[\mathrm{Cp}_{2}{ }_{2} \mathrm{Fe}\right] /$ $\left[\mathrm{Cp}_{2}{ }_{2} \mathrm{Fe}\right]^{+}\left(\mathrm{Cp}^{*}=\right.$ pentamethylcyclopentadienyl $)$ in DCM, $\mathrm{NBu}_{4} \mathrm{PF}_{6}$ as electrolyte and a sweep rate of $400 \mathrm{mV} \mathrm{s}^{-1},{ }^{b}$ no CV in DCM possible due to composition, measured in THF, ${ }^{c}$ complex in both DCM and THF not stable enough for CV measurements.

The forward peak potentials are comparable to structurally related $\mathrm{Ni}(\mathrm{II})$ salicylaldiminato complexes bearing a $\mathrm{N}$-terphenyl group. ${ }^{15}$ The oxidation is only partially reversible at a scan rate of 400 $\mathrm{mV} \mathrm{s}^{-1}$. Even at a scan rate of $2000 \mathrm{mV} \mathrm{s}^{-1}$ the process is not fully reversible, which indicates a highly instable Ni(III) species. The forward peak potentials of the oxygen bridged complexes are lower when compared to their methylene bridged counterparts (e.g E = $-98 \mathrm{mV}$ for $\mathbf{4}-\mathbf{C H}_{3}-\mathbf{I 2}$ vs. $\mathrm{E}=189 \mathrm{mV}$ for $\mathbf{4}-\mathbf{C H}_{3}-\mathbf{I 2}$ ). This difference is particularly pronounced for the complexes with diiodo substitution on the salicyl ring. Additionally, the forward peak potentials are highly dependent on the remote substituent $\mathrm{R}^{1}$ : The more electron-donating $\mathrm{R}^{1}$, the higher the electron density at the Ni-atom (e.g. $\mathrm{E}=192 \mathrm{mV}$ for $\mathbf{4}-\mathbf{C F}_{3}-\mathbf{I 2}$ vs. $\mathrm{E}=-\mathbf{9} 8 \mathrm{mV}$ for $\mathbf{4}-\mathbf{C H}_{\mathbf{3}^{-}}$ I2). This effect can be seen for both the oxygen- and the methylene bridged complexes and indicates a transfer of the electron density of the remote substituents to the Ni-atom. Interestingly, the effect of $\mathrm{R}^{1}$ is higher for the oxygen bridged complexes compared to the methylene bridged complexes. This indicates a more efficient transfer of the electron density to the $\mathrm{Ni}$-atom. According to crystal structures (see below) the lone electron pairs of the oxygen atoms are located above and below the Ni-atom. The electron density of the oxygen atoms is expected to be influenced by $\mathrm{R}^{1}$ and consequently this could impact the forward peak potentials of the $\mathrm{Ni}$-atom via the lone electron pairs. This mechanism is not possible for the methylene bridged complexes.

$X$-ray crystallography. Crystals suitable for x-ray crystallography could be grown for four anthryl substituted complexes. For the diiodo substituted complexes either no crystals were obtained or, in case of one diiodo substituted complex $\mathbf{4}-\mathbf{C F}_{3}-\mathbf{I 2}$, yielded in a decomposition product: $\left[\mathrm{NiI}_{2}(\mathrm{pyr})_{2}\right]$ (see SI). This agrees with a generally limited stability of the oxygen bridged complexes with diiodo substitution on the salicyl ring in solution. The decomposition product is tetrahedral and therefore presumably paramagnetic and not detectable in NMR experiments.

Regarding the oxygen bridged complexes, crystals suitable for $\mathrm{x}$ ray crystallography were obtained for $\mathbf{4}-\mathbf{C H}_{3}$-ant and $\mathbf{4}-\mathbf{H}$-ant by layering a saturated solution of the complexe in benzene with pentane (Figure 2).
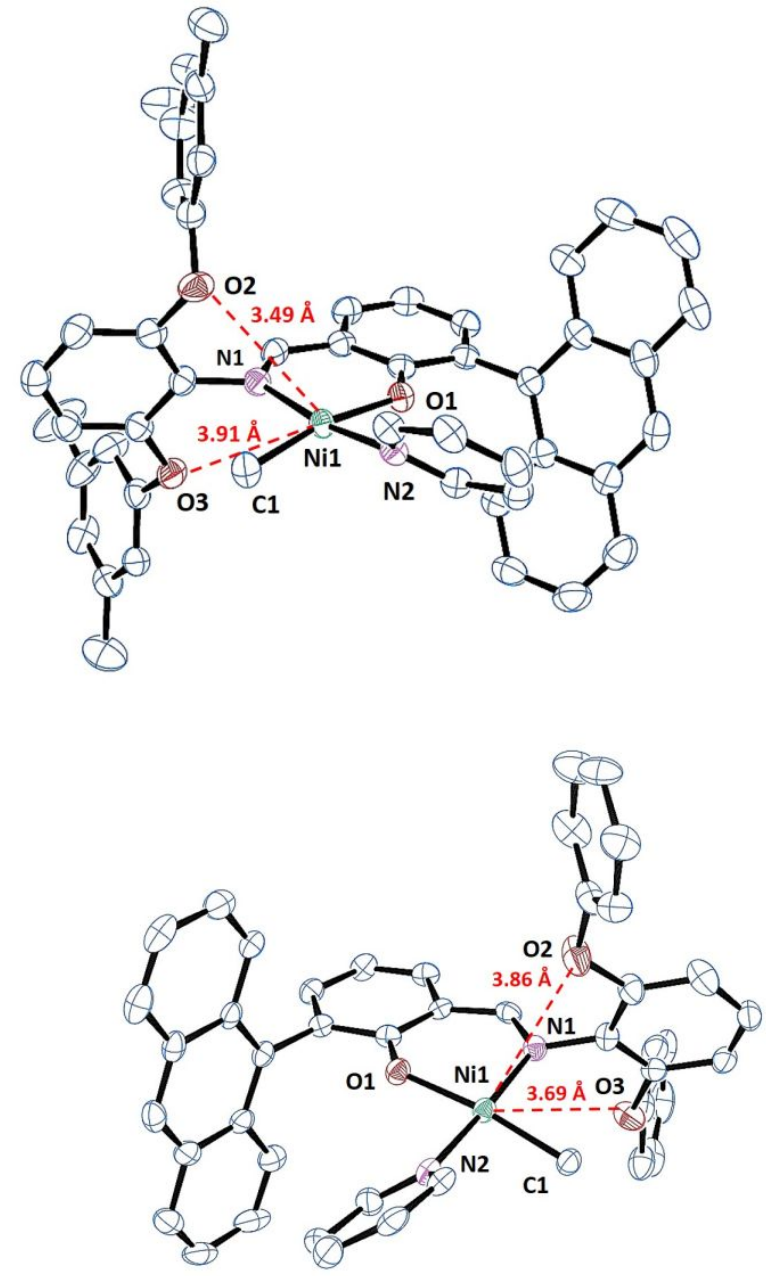

Figure 2: ORTEP (50\% probability ellipsoids, hydrogens are omitted for clarity) plots of structures determined by X-ray diffraction of 4-CH -ant (top) and 4-H-ant (bottom). The distance between the oxygen atoms of the $\mathrm{N}$-aryl moiety and the Ni-center is given.

The Ni-atom is coordinated nearly square-planar with the Ni-Me group coordinated trans to the oxygen atom of the salicylaldiminato group. The oxygen atoms on the $\mathrm{N}$-aryl ring ( $\mathrm{O} 2$ and $\mathrm{O} 3$ ) are located above and below the coordination plane of the metal center. The distance between the oxygen atoms and the $\mathrm{Ni}$ atom ranges between $3.49 \AA$ and $3.91 \AA$. The closest distance is larger compared to the sum of the van der Waals (vdW) radii determined by Bondi $(3.15 \AA)^{23}$, but smaller than the vdW radii determined by Batsanov $(3.55 \AA)^{24}$ or found by an empirical study $(3.9 \AA)^{25}$. Within this range of given vdW radii, an interaction between the oxygen atoms and the $\mathrm{Ni}$ atom might be possible, especially as the lone electron pairs point in the direction of the Niatom. These indications from the solid state structures of the catalyst precursors are indeed corroborated by theoretical studies of the intermediates of catalysis (vide supra).

For the methylene bridged complexes, solid state structures for 
8- $\mathrm{CH}_{3}$-ant and 8-CF $-\mathrm{CF}_{3}$-ant were obtained (Figure 3).
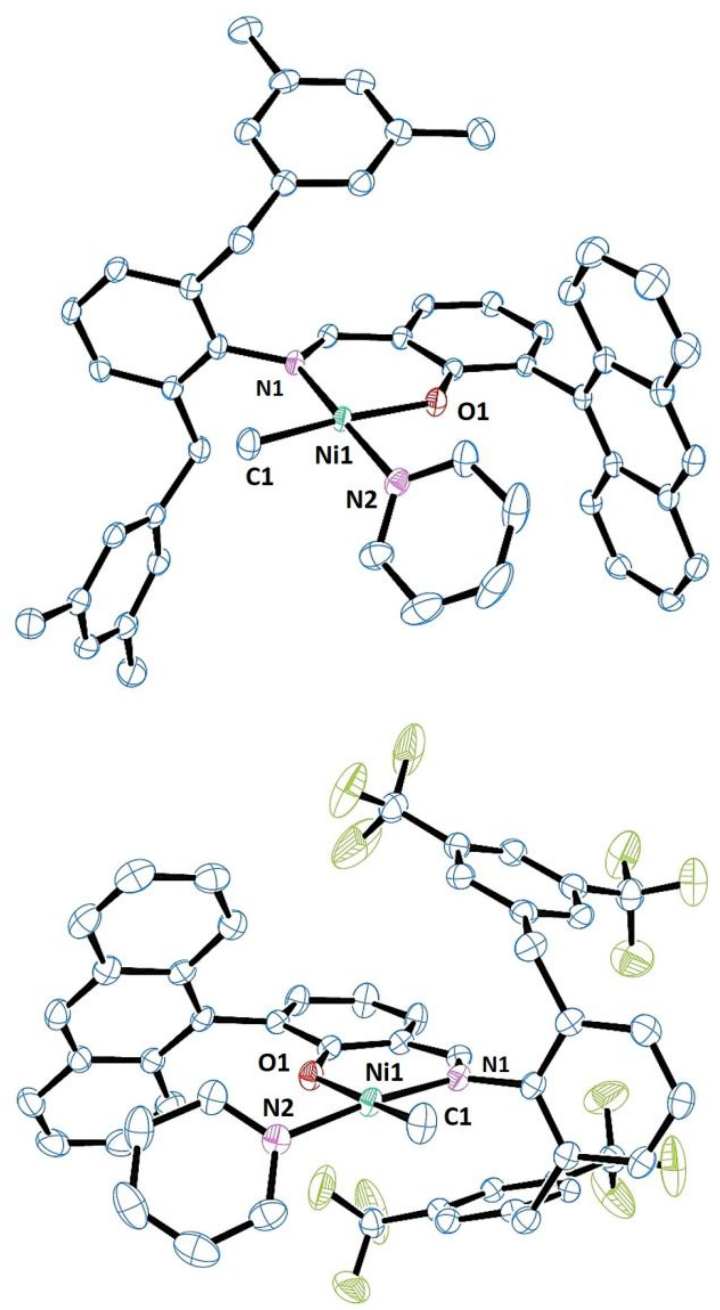

Figure 3: ORTEP (50\% probability ellipsoids, hydrogens are omitted for clarity) plots of structures determined by X-ray diffraction of 8- $\mathbf{C H}_{3}$-ant (top) 8- $\mathbf{C F}_{3}$-ant (bottom).

The benzylic rings are located above and below the metal center. The structure in solution was elucidated by 2D NOESY NMR spectroscopy (see SI). This shows that the methylene group is also located in spatial proximity to the Ni-Me group. The methylene group is close enough to the $\mathrm{Ni}$ center to allow a $\mathrm{Ni} \cdots \mathrm{CH}_{2}$ interaction, whereas a $\mathrm{Ni} \cdots$ aryl interaction is unlikely due to the large distance between the Ni atom and the distal aryl rings.

Table 2: Oligomerization results with oxygen bridged catalyst precursors 4 .

47
48
50
51
52
53
54
56
57
58
59
60

$\begin{array}{lcccc}\# & \text { precatalyst } & \begin{array}{c}\mathbf{t} \\ {[\mathbf{m i n}]}\end{array} & \begin{array}{c}\mathbf{T} \\ {\left[{ }^{\circ} \mathbf{C}\right]}\end{array} & \begin{array}{c}\text { yie } \\ \text { (ma } \\ \text { flow } \\ \mathbf{[ g}]\end{array} \\ \mathbf{1} & \text { 4- } \mathrm{CH}_{3}-\mathrm{I} 2 & 60 & 30 & 5.4 \\ \mathbf{2} & 4-\mathrm{CH}_{3}-\mathrm{I} 2 & 30 & 50 & 3.2 \\ \mathbf{3} & 4-\mathrm{CH}_{3}-\mathrm{I} 2 & 30 & 70 & 1.3 \\ \mathbf{4} & \text { 4-H-I2 } & 60 & 30 & 2.4 \\ \mathbf{5} & \text { 4-H-I2 } & 30 & 50 & 2.5\end{array}$

$\begin{array}{cc}\begin{array}{c}\text { yield } \\ \text { (mass } \\ \text { flow) } \\ {[\mathbf{g}]^{\boldsymbol{a}}}\end{array} & \begin{array}{c}\text { TO } \\ {\left[\mathbf{1 0}^{3}\right.}\end{array} \\ 5.4 & \\ 3.2 & 19.3 \\ 1.3 & 4.6 \\ 2.4 & 8.6 \\ 2.5 & 8.9\end{array}$

\section{Ethylene Polymerization Experiments}

Oxygen bridged catalysts. All oxygen bridged catalysts 4 are active towards ethylene in pressure reactor experiments (Table 2). Productivities determined from the ethylene uptake amounts to $1.3 \mathrm{~g}$ and $17.6 \mathrm{~g}$, depending on the catalyst and the polymerization temperature. In general, the catalysts with anthryl substitution are more stable, especially at higher temperatures, and therefore more productive compared to the catalysts with diiodo substitution.

Products from butenes to oligomers with up to $1200 \mathrm{~g} \mathrm{~mol}^{-1}$ were obtained. Catalysts with $\mathrm{R}^{1}=\mathrm{H}$ or $\mathrm{CH}_{3}\left(\mathbf{4}-\mathrm{CH}_{3}-\mathbf{I 2}, \mathbf{4 - H}-\mathbf{I 2}, \mathbf{4}-\mathbf{C H}_{3}-\right.$ ant and 4-H-ant) oligomerize ethylene to low molecular weight products from $\mathrm{C}_{4}$ to roughly $\mathrm{C}_{22}$ (Figure 4).

Figure 4: GC-trace of the crude oligomerization mixture with 4-Hant at $50{ }^{\circ} \mathrm{C}, 40$ bar ethylene, $\mathrm{t}=30 \mathrm{~min}$. The obtained gaseous $\mathrm{C}_{4}$ products are largely lost upon venting the reactor.

The volatile products were removed, and the remaining non volatile products further analyzed. The oily products show no detectable melting or glass transition point. The molecular weight determined by NMR is roughly $300 \mathrm{~g} \mathrm{~mol}^{-1}$. The oligomers are moderately branched (between 53 and 81 branches per $1000 \mathrm{C}$ atoms), which corresponds to roughly one branch per chain. The branching increases with increasing polymerization temperature. The branches are mainly methyl branches, but ethyl and and propyl branches are also present (for a detailed microstructure analysis see SI).

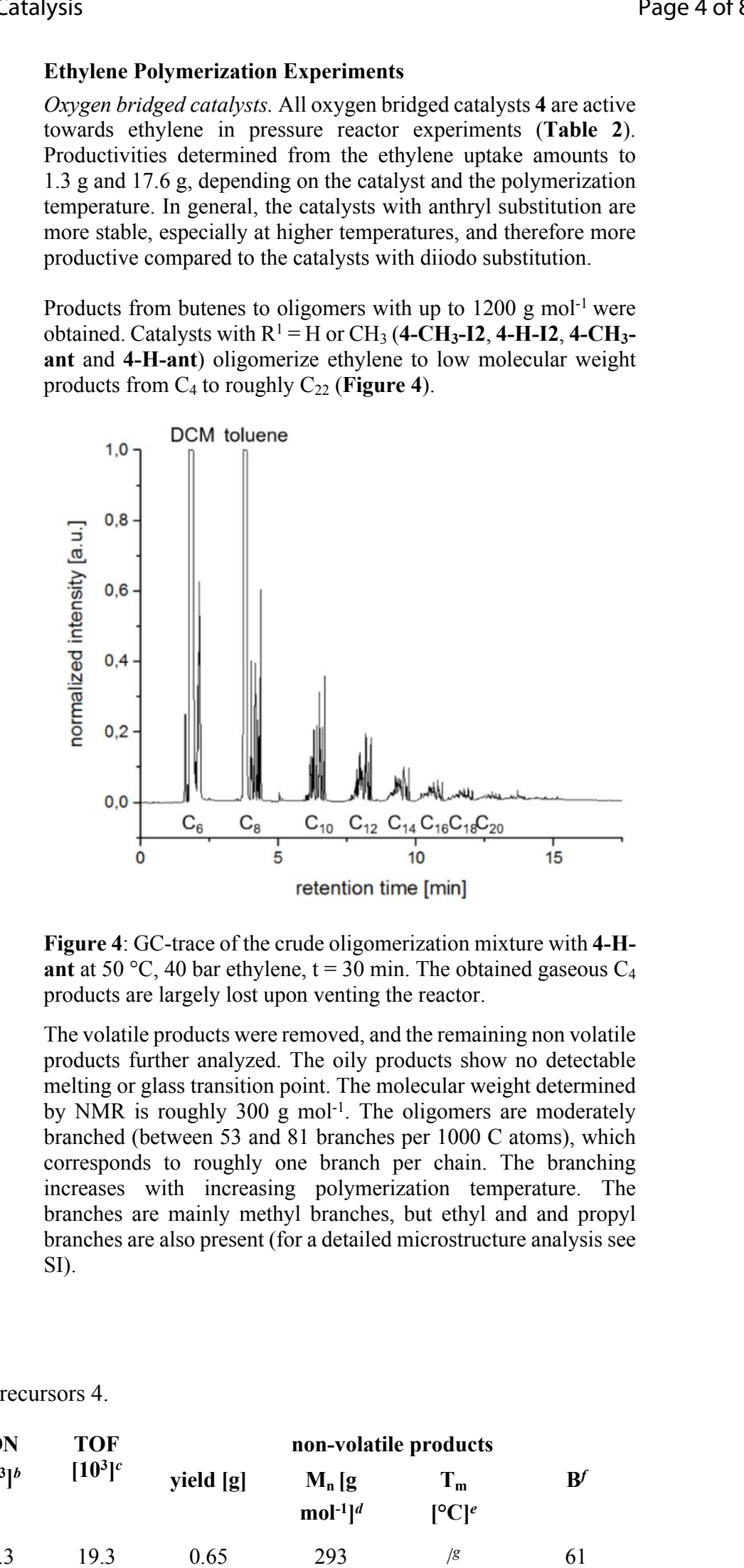

\section{TOF \\ $\left[10^{3}\right]^{c}$}

yield $[g]$

non-volatile products

0.61

9.3

0.17

8.6

1.43

17.9

1.69 


$\begin{array}{ccc}7 & 4-\mathrm{CF}_{3}-\mathrm{I} 2 & 30 \\ \mathbf{8} & \text { 4- } \mathrm{CF}_{3}-\mathrm{I} 2 & 30 \\ \mathbf{9} & \text { 4- } \mathrm{CF}_{3}-\mathrm{I} 2 & 30 \\ \mathbf{1 0} & \text { 4- } \mathrm{CH}_{3} \text {-ant } & 30 \\ \mathbf{1 1} & \text { 4- } \mathrm{CH}_{3} \text {-ant } & 30 \\ \mathbf{1 2} & \text { 4- } \mathrm{CH}_{3} \text {-ant } & 30 \\ \mathbf{1 3} & \text { 4-H-ant } & 30 \\ \mathbf{1 4} & \text { 4-H-ant } & 30 \\ \mathbf{1 5} & \text { 4-H-ant } & 30 \\ \mathbf{1 6} & \text { 4-CF } \text {-ant } & 30 \\ \mathbf{1 7} & \text { 4- } \mathrm{CF}_{3} \text {-ant } & 30 \\ \mathbf{1 8} & \text { 4- } \mathrm{CF}_{3} \text {-ant } & 30\end{array}$

70
30
50
70
30
50
70
30
50
70
30
50
70

$\begin{array}{cccc}1.3 & 4.6 & 9.3 & 0.73 \\ 1.4 & 5.0 & 10.0 & 0.33 \\ 2.0 & 7.1 & 14.3 & 1.82 \\ 1.5 & 5.35 & 10.7 & 1.06 \\ 3.3 & 11.8 & 23.6 & 1.10 \\ 7.4 & 26.4 & 52.9 & 2.43 \\ 6.6 & 23.5 & 47.1 & 1.50 \\ 4.3 & 15.4 . & 30.7 & 0.71 \\ 7.9 & 28.2 & 56.4 & 3.60 \\ 7.6 & 27.1 & 54.3 & 3.20 \\ 1.6 & 5.7 & 11.4 & 1.21 \\ 8.0 & 28.6 & 57.1 & 6.72 \\ 17.6 & 62.9 & 125.7 & 14.4\end{array}$

267
1022
810
896
386
275
290
338
321
321
1380
895
791

$\begin{array}{cc}/ g & 70 \\ 56,88 & 21 \\ 56,88 & 27 \\ 67 & 35 \\ / g & 51 \\ / g & 55 \\ / g & 69 \\ / g & 42 \\ / g & 51 \\ / g & 50 \\ 103 & 16 \\ 97 & 17 \\ 57,90 & 23\end{array}$

Oligomerization conditions: $100 \mathrm{~mL}$ of toluene, 40 bar of ethylene, $\mathrm{n}$ (cat.) $=10 \mu \mathrm{mol}, 1000 \mathrm{rpm} .{ }^{a}$ ethylene consumption determined by mass flow. ${ }^{b}$ in units of $\mathrm{mol} \mathrm{C}_{2} \mathrm{H}_{4}$ (mol of Ni) $)^{-1}$ from ethylene consumption as determined by mass flow. ${ }^{c}$ in $\mathrm{mol} \mathrm{C}_{2} \mathrm{H}_{4} \mathrm{x} \mathrm{mol}^{-1}[\mathrm{Ni}] \mathrm{x} \mathrm{h}^{-1}$ from ethylene consumption as determined by mass flow. ${ }^{d}$ Determined by ${ }^{1} \mathrm{H}-\mathrm{NMR}$ spectroscopy comparing the integrals of the unsaturated end groups with the integral of the backbone. ${ }^{e} \mathrm{~T}_{\mathrm{m}}$ determined by DSC, second heating cycle. ${ }^{f}$ Branches per $1000 \mathrm{C}$ atoms, determined by ${ }^{13} \mathrm{C}$ NMR spectroscopy (inverse gated decoupled). ${ }^{g}$ No melting or glass transition point detectable.

Catalysts with $\mathrm{R}^{1}=\mathrm{CF}_{3}$ or $\mathrm{H}$ oligomerize ethylene to solid, waxy products with a detectable melting point. The molecular weight lies between $800 \mathrm{~g} \mathrm{~mol}^{-1}$ and $1200 \mathrm{~g} \mathrm{~mol}^{-1}$ and the oligomers are moderately branched. The molecular weight decreases with increasing temperature, whereas the branching increases with increasing temperature. This correlation is expected, as with increasing temperature, $\beta-\mathrm{H}$ elimination is increased, which is the key step for both chain transfer and branching.
These findings indicate that chain walking and chain transfer is rather frequent for the oxygen bridged catalysts 4 , and especially prominent for the catalyst with $\mathrm{R}^{1}=\mathrm{CH}_{3}$ or $\mathrm{H}$.

Methylene bridged catalysts. The complexes $\mathbf{8}$ are also highly active in ethylene polymerization experiments but yield entirely different products (Table 3). All catalysts produced polymers with molecular weights between $32 \mathrm{~kg} \mathrm{~mol}^{-1}$ and $449 \mathrm{~kg} \mathrm{~mol}^{-1}$ and low branching densities (between 1.0 branches and 11.5 branches per $1000 \mathrm{C}$ atoms).

Table 3: Polymerization results with methylene bridged precatalysts $\mathbf{8}$.

\begin{tabular}{|c|c|c|c|c|c|c|c|c|c|c|}
\hline \# & pre-catalyst & $\begin{array}{l}\text { n (cat) } \\
{[\mu \mathrm{mol}]}\end{array}$ & $\begin{array}{c}\mathbf{T} \\
{\left[{ }^{\circ} \mathbf{C}\right]}\end{array}$ & $\begin{array}{c}\text { yield } \\
{[\mathrm{g}]}\end{array}$ & $\begin{array}{c}\text { TON } \\
{\left[10^{3}\right]^{a}}\end{array}$ & $\begin{array}{c}\text { TOF } \\
{\left[10^{3}\right.} \\
\left.\mathbf{h}^{-1}\right]^{b}\end{array}$ & $\begin{array}{c}\mathrm{M}_{\mathrm{n}}[\mathrm{kg} \\
\left.\mathrm{mol}^{-1}\right]^{\mathrm{c}}\end{array}$ & $\mathbf{P D I}^{\mathbf{c}}$ & $\underset{\left[{ }^{\circ} \mathbf{C}\right]^{d}}{\mathbf{T}_{\mathbf{m}}}$ & $\begin{array}{c}\mathrm{X} \\
{[\%]^{d}}\end{array}$ \\
\hline 1 & $8-\mathrm{CH}_{3}-\mathrm{I} 2$ & 10 & 30 & 1.9 & 6.8 & 13.6 & 224 & 1.6 & 126 & 53 \\
\hline 2 & $8-\mathrm{CH}_{3}-\mathrm{I} 2$ & 10 & 60 & 3.5 & 12.5 & 25.0 & 57 & 1.9 & 116 & 51 \\
\hline 3 & 8-H-I2 & 10 & 30 & 0.9 & 12.0 & 24.1 & 127 & 1.6 & 127 & 58 \\
\hline 4 & 8-H-I2 & 10 & 60 & 3.4 & 3.3 & 6.5 & 42 & 1.6 & 116 & 54 \\
\hline 5 & $8-\mathrm{CF}_{3}-\mathrm{I} 2$ & 10 & 30 & 1.8 & 6.4 & 12.9 & 192 & 1.4 & 133 & 59 \\
\hline 6 & $8-\mathrm{CF}_{3}-\mathrm{I} 2$ & 10 & 60 & 1.4 & 5.1 & 10.2 & 32 & 4.1 & 124 & 60 \\
\hline 7 & $8-\mathrm{CH}_{3}$-ant & 10 & 30 & 6.8 & 24.3 & 48.6 & 465 & 1.3 & 134 & 52 \\
\hline $8^{f}$ & $8-\mathrm{CH}_{3}$-ant & 10 & 60 & 10.6 & 37.9 & 75.7 & n. d. & n.d. & 117 & 56 \\
\hline 9 & 8- $\mathrm{CH}_{3}$-ant & 5 & 60 & 6.3 & 45.0 & 90.0 & 123 & 1.5 & 122 & 53 \\
\hline $10^{g}$ & 8-H-ant & 10 & 30 & 7.8 & 27.9 & 55.7 & 449 & 1.3 & 134 & 53 \\
\hline 11 & 8-H-ant & 10 & 60 & 13.4 & 47.9 & 95.7 & 131 & 1.6 & 125 & 52 \\
\hline 12 & $8-\mathrm{CF}_{3}$-ant & 10 & 30 & 3.9 & 13.9 & 27.9 & 307 & 1.3 & 133 & 57 \\
\hline 13 & $8-\mathrm{CF}_{3}$-ant & 10 & 60 & 15.6 & 55.7 & 111.4 & 161 & 1.6 & 129 & 57 \\
\hline
\end{tabular}

Polymerization conditions: $100 \mathrm{~mL}$ of toluene, 40 bar of ethylene, $\mathrm{t}=30 \mathrm{~min}, 1000 \mathrm{rpm}$. ${ }^{a}$ in units of $\mathrm{mol} \mathrm{C}_{2} \mathrm{H}_{4}\left(\mathrm{~mol} \mathrm{of} \mathrm{Ni}^{-1}\right.$. ${ }^{b}$ in mol C $\mathrm{m}_{2} \mathrm{H}_{4}$ $\mathrm{x} \mathrm{mol}^{-1}[\mathrm{Ni}] \mathrm{x} \mathrm{h}^{-1}$. ${ }^{c}$ Determined by GPC versus linear polyethylene standards at $160{ }^{\circ} \mathrm{C} ; \mathrm{PDI}=\mathrm{M}_{\mathrm{w}} / \mathrm{M}_{\mathrm{n}}{ }^{d} \mathrm{Crystallinity}$ determined by DSC, second heating cycle. ${ }^{e}$ Branches per $1000 \mathrm{C}$ atoms, determined by ${ }^{13} \mathrm{C}$-NMR spectroscopy (inverse gated decoupled). ${ }^{f}$ Temperature control lost, temperature rose to $90^{\circ} \mathrm{C}$, stopped after $8.5 \mathrm{~min}$, new experiment with half of the catalyst loading performed (line 9). ${ }^{g}$ pressurized once to 40 bar; pressure after 30 min: 38 bar. 
The microstructure of the polymers is determined by the reaction temperatures, higher temperatures favoring branch formation. Additionally catalysts with anthryl substitution on the salicylaldiminato ring produce more linear polyethylene with a higher molecular weight when compared to the catalysts with diodo substitution. Other than for the O-bridged complexes 4, for the methylene bridged catalysts no significant influence of the distal aryl rings' substituents $\left(\mathrm{R}^{1}\right)$ are observed.

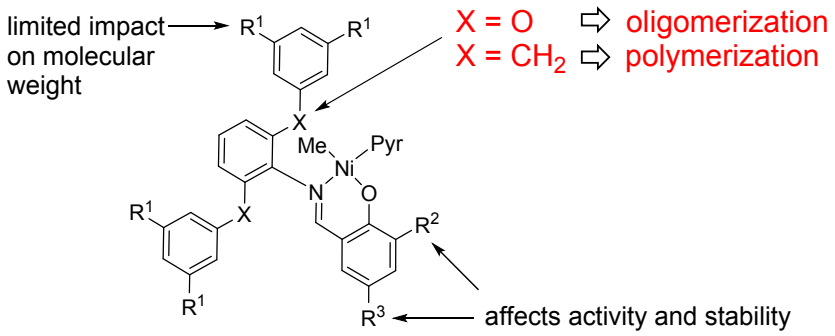

Figure 5: Summary of impact of catalyst structure on properties.

In summary, the catalytic properties (Figure 5) revealed a strong propensity of the oxygen-bridged catalysts 4 for $\beta-\mathrm{H}$ elimination, resulting in formation of low molecular weight branched products. This strongly contrasts with the properties of the reference system (8).

\section{Density functional theory calculations.}

To rationalize the effect of the bridge on the catalytic properties, two exemplary catalysts (4-CH$-\mathbf{C} 2$ and $\left.\mathbf{8}-\mathbf{C H}_{3}-\mathbf{I 2}\right)$ were studied by DFT methods.

For $\mathrm{Ni}(\mathrm{II})$ salicylaldiminato complexes in general insertion chain growth occurs from the alkyl olefin complex with the growing chain $c i s$ to the salicylaldiminato oxygen. Alternatively, from this species ethylene can be decoordinated to form a cis ß-agostic complex providing an entry to further branching and chain transfer pathways. ${ }^{2,15,26-27}$

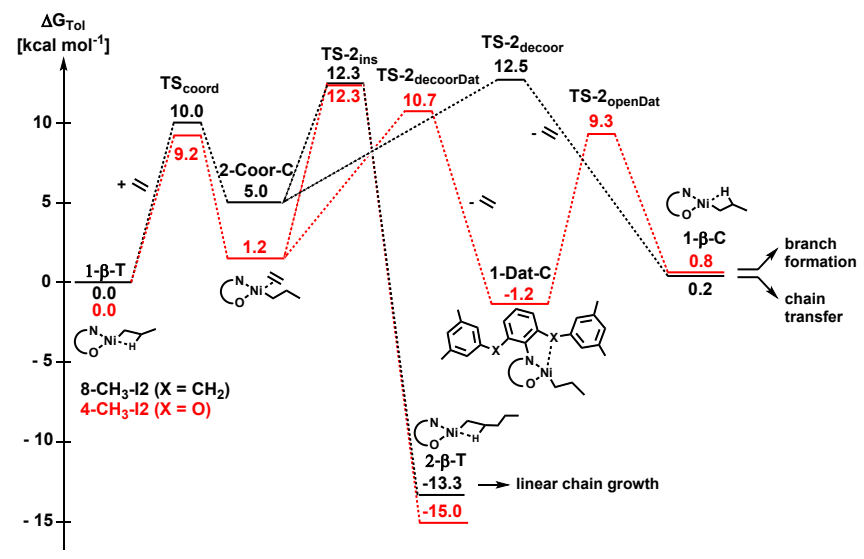

Figure 6. Linear chain growth pathway and two potential pathways for the decoordination of ethylene to form $\mathbf{1 - \beta - C}$ from 1- $\boldsymbol{\beta}-\mathbf{T}$. Free energies $\left(\Delta \mathrm{G}_{\mathrm{Tol}}\right.$ in $\left.\mathrm{kcal} \mathrm{mol}^{-1}\right)$.

For the oxygen-bridged complex studied (4-CH $-\mathbf{I 2})$, decoordination of ethylene from the cis alkyl-olefin complex (2Coor-C) occurs through displacement of the olefin by the oxygen lone pair to form the intermediate 1-Dat-C (Figure 6 and Figure 7, for the full study cf. the SI). This intermediate is rather stable but barely not yet an energetic sink impeding catalysis, being similar in energy to the $\mathbf{1 - \beta} \mathbf{\beta}$ - T starting point and the corresponding $\mathbf{1 - \beta}-\mathbf{C}$ isomer. The latter is formed from the aforementioned intermediate 1-Dat-C through displacement of the $\mathrm{Ni} \cdots \mathrm{O}$ interaction by an agostic one. From 1- $\beta-\mathbf{C}$ branch formation and chain transfer occur. Notably, the $\mathrm{Ni} \cdots$ aryl interactions assisting ethylene decoordination in N-Terphenyl-catalysts are considerably weaker, and unlike the oxygen-coordinated 1-Dat-C the $\mathrm{Ni} \cdots$ aryl intermediate is high in energy compared to the other species involved. ${ }^{13}$

By comparison, for the reference system $\mathbf{8}-\mathbf{C H}_{3}-\mathbf{I} \mathbf{2}$ no such assisted two-step pathway is available, neither an interaction of the methylene bridge nor the distal aryl ring with $\mathrm{Ni}$ is available, and $\mathbf{1}-\boldsymbol{\beta}-\mathbf{C}$ forms directly from $\mathbf{2}$-Coor-C with a corresponding energy barrier.

The key transition state for the olefin displacement with 4-CH$-\mathbf{C}$ system is a five coordinated complex (Figure 7a) with the leaving ethylene occupying an apical position and the oxygen coordinating in the ligand plane $(\mathrm{O} \cdots \mathrm{Ni}$ distance $2.17 \AA)$. The following intermediate (Figure 7b) exhibits a planar quadrant coordination geometry with the oxygen weekly coordinated to the metal at a distance of $1.98 \AA$. a)

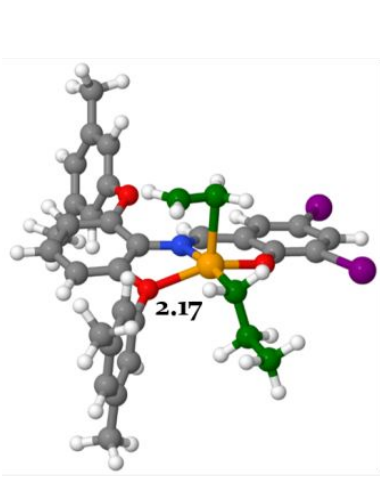

b)

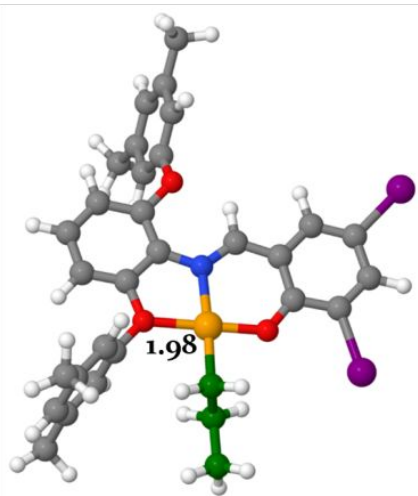

Figure 7. Optimized structures of a) TS-2 decoorDat $_{\text {and b) 1-Dat-C }}$ for the system 4-CH$-\mathbf{C}$. Distances are in $\AA$. Carbon atoms of monomer and growing chain are highlighted in green.

It is worth noting that the alternative displacement of ethylene by the $\eta^{2}$-coordination of the distal aryl ring to the metal center requires a higher energy barrier (of about $21 \mathrm{kcal} \mathrm{mol}^{-1}$, see SI).

In addition to this $\mathrm{Ni} \cdots \mathrm{O}$ interaction, the bridge also increases the flexibility of the ligand framework. This is reflected by low energy barriers for the isomerization process (1- $\boldsymbol{\beta}$ - T to $\mathbf{1 - \beta}-\mathbf{C})$ for both systems (12.5 and 10.7 for $\mathbf{8}-\mathbf{C H}_{\mathbf{3}}-\mathbf{I} \mathbf{2}$ and $\mathbf{4}-\mathbf{C H}_{3}-\mathbf{I} \mathbf{2}$, respectively). This flexibility releases steric pressure especially in the crowded five coordinated transition states TS- $\mathbf{2}_{\text {decoorDat }}$ and TS- $\mathbf{2}_{\text {decoor }}$.

Comparing the overall energetics of the key steps for both catalysts 8- $\mathbf{C H}_{3}-\mathbf{I 2}$ and 4-CH$-\mathbf{C}$, the latter features the lowest isomerization barrier $\left(10.7 \mathrm{kcal} \mathrm{mol}^{-1}\right.$, $\mathrm{cf}$. TS-2 $\left.\mathbf{2}_{\text {decoorDat }}\right)$ due to the oxygen assisted decoordination of ethylene. This renders formation of the cis agostic complex, responsible for branch formation and chain growth, competitive with chain growth. This agrees with the experimentally observed formation of ethylene dimers and low molecular weight oligomers, vs. high molecular weight linear polymer with 8-CH $\mathbf{-}-\mathbf{I 2}$.

The ethylene decoordination rate determining transition state is 1.6 $\mathrm{kcal} \mathrm{mol}^{-1}$ lower than the insertion transition state (see again Figure 6 ) with the oxygen-coordinated intermediate 1-Dat-C being only $1.2 \mathrm{kcal} \mathrm{mol}^{-1}$ more stable than 1- $\beta$-T and not blocking the active site. These results agree with the experimental observation that 
system 4-CH$-\mathbf{C H}_{3}-\mathbf{2}$ displays a high catalytic activity towards ethylene but produces highly branched ethylene oligomers.

\section{CONCLUSION}

These comprehensive studies of a range of different $\mathrm{Ni}$ (II) salicylaldiminato complexes with -OAryl motifs show, that this common motif drastically steers the catalysts' selectivity towards short chain products. Ethylene dimers and branched oligomers $\left(\mathrm{C}_{4}\right.$, $\left.\mathrm{C}_{6}, \mathrm{C}_{8} \ldots\right)$ are the major compounds formed. By comparison, catalysts with $-\mathrm{CH}_{2}$ Aryl groups and an otherwise identical structure afford largely linear to moderately branched polyethylenes with molecular weights exceeding $M_{n} 100.000 \mathrm{~g}$ $\mathrm{mol}^{-1}$ under the same reaction conditions. Catalyst activities are on the same order in both cases. This suggests that the -OAryl motif indeed promotes chain transfer primarily. Chain growth is affected to a minor extent, if at all. With both types of catalysts the maximum observed activities amount to $10^{5}$ turnovers per hour.

Theoretical studies support that an $\mathrm{O} \cdots \mathrm{Ni}$ interaction accounts for the experimental finding. In line with previous studies, insertion chain growth occurs from the alkyl olefin complex with the growing alkyl chain cis to the oxygen donor. The alternative decoordination of ethylene would form the cis agostic complex, from which BHE occurs. Displacement of ethylene by Ocoordination opens up a low energy pathway to formation of the cis agostic complex. The calculated energy of the O-coordinated intermediate underlines that, in this system, coordination of the neighbouring group is competitive with substrate coordination. Its energy compares to that of the aforementioned alkyl-olefin and agostic complex, which are both key intermediates. This corresponds with the experimental observation of a strongly altered selectivity at a yet uncompromised activity, that is, the $\mathrm{O} \cdots \mathrm{Ni}$ interaction is just not too strong to provide an undesirable unactive trapped dormant state of the catalyst.

In summary, these findings support the understanding of how chain walking can be controlled by neighboring group interactions. Particularly, they stake out the desirable and permissible strength of such interactions and hereby provide guidelines for the design of advanced polymerization catalysts that exploit 'secondary' interactions.

\section{AUTHOR INFORMATION}

\section{Corresponding Author}

*stefan.mecking@uni-konstanz.de

*lcaporaso@unisa.it

\section{Notes}

The authors declare no competing financial interest.

\section{ASSOCIATED CONTENT}

\section{Supporting Information}

Detailed experimental procedures, NMR spectra, crystallographic data including CCDC numbers, complete polymerization experiment information, analysis of the oligomerization polymerizations and computational details (PDF).

The Supporting Information is available free of charge on the ACS Publications website.

\section{ACKNOWLEDGMENT}

Financial support by the DFG (Me 1388/14-1) is gratefully acknowledged. We thank Steffen Oßwald for assistance with the CV measurements and Lars Bolk for DSC and GPC measurements.

\section{REFERENCES}

1. Nakamura, A.; Ito, S.; Nozaki, K., Coordination-Insertion Copolymerization of Fundamental Polar Monomers. Chem. Rev. 2009, 109, 5215-5244.

2. Johnson, L. K.; Killian, C. M.; Brookhart, M., New Pd(II)- and $\mathrm{Ni}(\mathrm{II})$-Based Catalysts for Polymerization of Ethylene and $\alpha$ Olefins. J. Am. Chem. Soc. 1995, 117, 6414-6415.

3. Kenyon, P.; Mecking, S., Pentafluorosulfanyl Substituents in Polymerization Catalysis. J. Am. Chem. Soc. 2017, 139, 1378613790.

4. Osichow, A.; Rabe, C.; Vogtt, K.; Narayanan, T.; Harnau, L.; Drechsler, M.; Ballauff, M.; Mecking, S., Ideal Polyethylene Nanocrystals. J. Am. Chem. Soc. 2013, 135, 11645-11650.

5. Wiedemann, T.; Tchernook, A.; Göttker-Schnetmann, I.; Mecking, S.; Bessel, M.; Omeis, J.; Frank, A.: Ethylene-based polymer as defoamer additive. EP2891511 A1. Priority: November $22,2013$.

6. Wiedemann, T.; Voit, G.; Tchernook, A.; Roesle, P.; GöttkerSchnetmann, I.; Mecking, S., Monofunctional Hyperbranched Ethylene Oligomers. J. Am. Chem. Soc. 2014, 136, 2078-2085.

7. Younkin, T. R.; Connor, E. F.; Henderson, J. I.; Friedrich, S. K.; Grubbs, R. H.; Bansleben, D. A., Neutral, Single-Component Nickel (II) Polyolefin Catalysts that Tolerate Heteroatoms. Science 2000, 287, 460-462.

8. Johnson, L. K.; Bennett, A. M. A.; Ittel, S. D.; Wang, L.; Parthasarathy, A.; Hauptman, E.; Simpson, R. D.; Feldman, J.; Coughlin, E. B. (E. I. du Pont de Nemours \& Co., USA) International Patent WO 98/30609, 1998.

9. Göttker-Schnetmann, I.; Korthals, B.; Mecking, S., WaterSoluble Salicylaldiminato Ni(II)-Methyl Complexes: Enhanced Dissociative Activation for Ethylene Polymerization with Unprecedented Nanoparticle Formation. J. Am. Chem. Soc. 2006, 128, 7708-7709.

10. Leblanc, A.; Grau, E.; Broyer, J.-P.; Boisson, C.; Spitz, R.; Monteil, V., Homo- and Copolymerizations of (Meth)Acrylates with Olefins (Styrene, Ethylene) Using Neutral Nickel Complexes: A Dual Radical/Catalytic Pathway. Macromolecules 2011, 44, 3293-3301.

11. Radlauer, M. R.; Buckley, A. K.; Henling, L. M.; Agapie, T., Bimetallic Coordination Insertion Polymerization of Unprotected Polar Monomers: Copolymerization of Amino Olefins and Ethylene by Dinickel Bisphenoxyiminato Catalysts. J. Am. Chem. Soc. 2013, 135, 3784-3787.

12. Mu, H.; Pan, L.; Song, D.; Li, Y., Neutral Nickel Catalysts for Olefin Homo- and Copolymerization: Relationships between Catalyst Structures and Catalytic Properties. Chem. Rev. 2015, 115, 12091-12137.

13. Zuideveld, M. A.; Wehrmann, P.; Röhr, C.; Mecking, S., Remote Substituents Controlling Catalytic Polymerization by Very Active and Robust Neutral Nickel(II) Complexes. Angew. Chem. Int. Ed. 2004, 43, 869-873.

14. Göttker-Schnetmann, I.; Wehrmann, P.; Röhr, C.; Mecking, S., Substituent Effects in $\left(\kappa^{2}-\mathrm{N}, \mathrm{O}\right)$-Salicylaldiminato Nickel(II)-Methyl Pyridine Polymerization Catalysts: Terphenyls Controlling Polyethylene Microstructures. Organometallics 2007, $26,2348-2362$. 
15. Falivene, L.; Wiedemann, T.; Göttker-Schnetmann, I.; Caporaso, L.; Cavallo, L.; Mecking, S., Control of Chain Walking by Weak Neighboring Group Interactions in Unsymmetrical Catalysts. J. Am. Chem. Soc. 2018, 140, 1305-1312.

16. Stephenson, C. J.; McInnis, J. P.; Chen, C.; Weberski, M. P.; Motta, A.; Delferro, M.; Marks, T. J., Ni(II) Phenoxyiminato Olefin Polymerization Catalysis: Striking Coordinative Modulation of Hyperbranched Polymer Microstructure and Stability by a Proximate Sulfonyl Group. ACS Catal. 2014, 4, 999-1003.

17. Li, M.; Wang, X.; Luo, Y.; Chen, C., A Second-CoordinationSphere Strategy to Modulate Nickel- and Palladium-Catalyzed Olefin Polymerization and Copolymerization. Angew. Chem. Int. Ed. 2017, 56, 11604-11609.

18. Zhai, F.; Solomon, J. B.; Jordan, R. F., Copolymerization of Ethylene with Acrylate Monomers by Amide-Functionalized $\alpha$ Diimine Pd Catalysts. Organometallics 2017, 36, 1873-1879.

19. Hansch, C.; Leo, A.; Taft, R. W., A Survey of Hammett Substituent Constants and Resonance and Field Parameters. Chem. Rev. 1991, 91, 165-195.

20. Hu, X.; Dai, S.; Chen, C., Ethylene Polymerization by Salicylaldimine Nickel(ii) Complexes Containing a Dibenzhydryl Moiety. Dalton Trans. 2016, 45, 1496-1503.
21. Carroll, W. R.; Pellechia, P.; Shimizu, K. D., A Rigid Molecular Balance for Measuring Face-to-Face Arene-Arene Interactions. Org. Lett. 2008, 10, 3547-3550.

22. Manolikakes, G.; Schade, M. A.; Hernandez, C. M.; Mayr, H.; Knochel, P., Negishi Cross-Couplings of Unsaturated Halides Bearing Relatively Acidic Hydrogen Atoms with Organozinc Reagents. Org. Lett. 2008, 10, 2765-2768.

23. Bondi, A., van der Waals Volumes and Radii. J. Phys. Chem. 1964, 68, 441-451.

24. Batsanov, S. S., Van der Waals Radii of Elements. Inorg. Chem. 2001, 37, 871-885.

25. Alvarez, S., A Cartography of the Van Der Waals Territories. Dalton Trans. 2013, 42, 8617-8636.

26. Hicks, F. A.; Brookhart, M., A Highly Active AnilinotroponeBased Neutral Nickel(II) Catalyst for Ethylene Polymerization. Organometallics 2001, 20, 3217-3219.

27. Chan, M. S. W.; Deng, L.; Ziegler, T., Density Functional Study of Neutral Salicylaldiminato Nickel(II) Complexes as Olefin Polymerization Catalysts. Organometallics 2000, 19, 2741-2750.

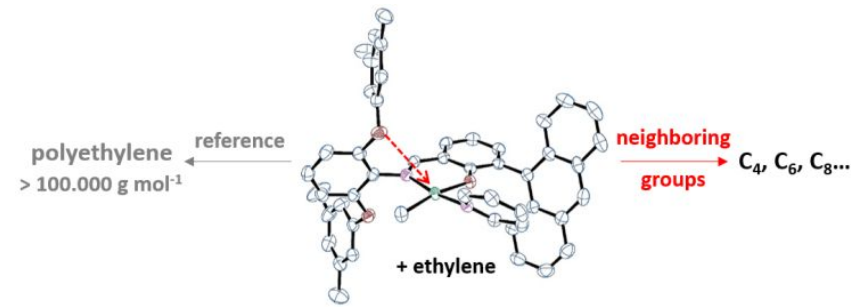

